\title{
CON LOS OJOS EN LA PARÁBOLA. LA MIRADA EN LA FUENTE DEL CÁNTICO SANJUANISTA Y EN EL RELATO DE LA PRINCESA DE SEFER HA-ZOHAR
}

\author{
Fabio Samuel Esquenazi \\ Universidad de Buenos Aires \\ ISER-Instituto Superior de Estudios Religiosos \\ esquenazi@filo.uba.ar
}

Palabras clave: mirada, Cántico, Zohar, mística, parábola.

KEY WORDS: vision, Cántico, Zohar, mysticism, parable.

"Excelso es Yahveh, y ve al humilde"

Salmo 138 (137), 6

Como advierten Paola Elia y María Jesús Mancho en la introducción (XXXVII-CXIX) a su edición del Cántico espiritual y la poesía completa sanjuanistas, no se puede ya contemplar el fenómeno de la literatura mística española sino desde una óptica multicultural, capaz de abordar su riqueza como resultado del complejo entramado de contactos culturales propio de todas las manifestaciones de lo hispánico. El paradigma del mestizaje español, diverso y tan profundamente atractivo, resulta incompleto sin un esfuerzo por ahondar, entre otros aspectos, en las corrientes literarias y filosóficas hebreas, musulmanas y nórdicas de las que se nutrió. En este contexto, mi interés por el trabajo de recuperación hermenéutica que un escritor místico realiza con el lenguaje ha hecho que me enfoque en el modo de conformación de la mirada en la escritura de San Juan de la Cruz y en el juego de intertextualidades que dicho proceso establece con las fuentes bíblicas y mediterráneas, particularmente con la mística judía, con la que mantiene importantes contactos. 
Dicho esto, hoy también sabemos que para entender en la obra de Juan de la Cruz el uso que allí se hace de la lengua, debemos atenernos, quizá como en ningún otro autor, a la jerarquización simbólico-sensorial de su escritura. En especial, a partir de las investigaciones de Elizabeth Wilhelmsen comprendemos mejor en este modelo de escritor místico (Mancho Duque) la profunda vinculación entre percepción espiritual e imagen poética, inscrita en el más amplio marco de relaciones entre experiencia y expresión, particularmente la importancia que este "doctor de las nadas" otorga al sentido del oído en el plano natural y en el plano místico. Sin embargo, hasta la fecha la crítica no ha prestado suficiente atención a los vínculos con la tradición cabalística, en particular la de raíz zohárica, presentes en el proceso de configuración de la mirada de los textos del Reformador del Carmelo, no obstante la centralidad -equiparable con la del oídoque a nuestro juicio ocupa en su doctrina de los sentidos espirituales, entendidos como exigencia interna del proceso purgativo que lleva a la unión con Dios.

La dimensión de esta deuda hermenéutica se evidencia a partir de una atenta lectura del corpus central de la Cábala, el Sefer ha-Zohar (o "Libro del resplandor")" única obra de la literatura rabínica postalmúdica que alcanzó estatus canónico en el judaísmo, junto con la Biblia hebrea, la Mishná y la Guemará. El Zohar postula la estrecha vinculación entre el estudio intenso de la Torá, el proceso de unión del individuo con Dios o devequt ${ }^{2}$ -entendido como apego o adhesión a su voluntad-, y la preeminencia del medio visual para la revelación y el conocimiento del sentido oculto del texto sagrado. Dicho proceso se encuentra en sintonía, entendemos, con el admirable tratamiento de la mirada de la estrofa XI -y la XII que la contextualiza- de la primera redacción de Cántico espiritual o Cántico " $A$ " $(C A)^{3}$. Tal similitud es especialmente sugerente si se contrasta, por ejemplo, la precitada sección de las Canciones sanjuanistas con parte del discurso pronunciado por el misterioso anciano de Sava de-Mishpatim del texto zohárico, cuyo cotejo arroja coincidencias significativas para la hermenéutica de los sentidos espirituales en Juan de la Cruz y viene en nuestro auxilio al proponer como hipótesis la posible construcción de la mirada como símbolo místico en la escritura de este carmelita, según los postulados de la escuela francesa de Jean Baruzi ${ }^{4}$.

1 A lo largo de este artículo citaremos, en todos los casos, por la edición académica inglesa más confiable, The Zohar. Pritzker Edition, respetando su condición de texto canónico. La traducción al español, así como los énfasis y agregados, son nuestros.

${ }^{2}$ Véase, por ejemplo, Zohar II: 213 b, donde se establece un paralelo entre la muerte y el ascenso nocturno del alma al Reino Superior, en el contexto de la exégesis del libro de Jonás (compárese, asimismo, II: 217a y III: 36a).

${ }^{3}$ Que en este trabajo hemos de citar, junto con los textos seleccionados de la segunda redacción $(C B)$, por la clásica edición de Lucinio Ruano de la Iglesia (en adelante, Obras). Los énfasis y aclaraciones también nos corresponden.

${ }^{4}$ Cf. a este respecto su desarrollo central en Baruzi (249-666). 
En este trabajo, nos centraremos solo en un ejemplo de la coincidencia señalada: la preeminencia del lenguaje visual en la dinámica textual de la "parábola de la princesa" de Sava de-Mishpatim [Zohar II, 99a-b], y en las dos primeras liras de la transformación amorosa -XI y XII- de $C A$. Nos apoyaremos, para ello, en una adecuada lectura de Zohar II, 98b, con la que intentaremos demostrar la posición de privilegio simbólico que comparten el verdadero visionario místico judío, el maskil-llamado el iluminado o sabio lleno de ojos-, y Juan de la Cruz, en cuanto al medio común (el cristal luminoso) puesto en juego en ambas experiencias místicas, y cuya referencia textual apunta hacia un tipo de revelación privilegiada.

Comencemos por señalar que toda la obra poética de Juan de la Cruz, de manera especial las Canciones entre el alma y el esposo -denominación original de Cántico espiritual-, está profundamente atravesada por la temática de los ojos, la visión y la mirada. Según el esquema de $C A$, a la sección inicial de la ausencia desconcertante e insoportable, constituida por las tres primeras estrofas que remiten a la purgación de los sentidos, le siguen el espacio reservado a la "meditación de las cosas espirituales" de las canciones IV y V (según se aclara en la segunda redacción, $C B, 22,3$, Obras 659), y el ingreso a la vida contemplativa que comienza en la sexta estrofa, en dirección a la lira que puede ser leída como eje argumental del poema, la XI, escenario privilegiado de una primera experiencia transformante. Allí tendrá lugar la visión de la divinidad y el desposorio espiritual, forma inicial de unyio mistica o cognitio Dei experimentalis para la tradición cristiana.

Recordémosla en todo su esplendor simbólico:

¡Oh cristalina fuente

si en esos tus semblantes plateados

formases de repente

los ojos deseados

que tengo en mis entrañas dibujados! (Obras 437-438).

José Ángel Valente, en su breve esbozo de una posible teología de la mirada en Juan de la Cruz, al analizar esta estrofa que describe el inicio de su experiencia del éxtasis, señala cómo la dinámica de la unión transformante con Dios es principalmente una dinámica de la visión. Lo expresa de este modo:

La canción XI, punto de cesación [del] movimiento [de búsqueda anhelante del Amado], es la identificación del lugar escondido, el término de la busca. El Amado ha huido hacia adentro [...] hacia el fondo o sustancia del alma. La Amada lo lleva en sus entrañas. Pero no lo lleva a modo de imagen -las imágenes se han extinguido-sino a modo de mirada [de allí]: "los ojos deseados / que tengo en mis entrañas dibujados". La Amada se constituye en su interior [es decir, en sus entrañas] como 
mirada del Amado. Está la Amada grávida de una mirada. [...] Pide a la fuente que la ayude en su alumbramiento, que es el alumbramiento de un mirar. El alumbramiento del mirar del otro: del otro de sí, del infinitamente otro que la constituye. No pide ver, pide ser vista. Porque la plenitud del ser es ser plenamente en la mirada del Amado [...] (Valente 80-81, el énfasis es nuestro).

Lo que se aprecia en Juan de la Cruz, entonces, es que la experiencia de unión con la divinidad se consuma a través de la visión, experiencia cuasi absoluta en este estadio del fenómeno místico y, al mismo tiempo, medio preeminente de conocimiento directo de lo Absoluto.

Ahora bien, como sabemos, el Sefer ha-Zohar, el gran compendio de cábala española medieval, es una teosofía judía, es decir, una doctrina mística que se propone conocer y detallar los misteriosos modos de acción del Dios de Israel, cuya palabra revelada -la Torá- es estudiada a partir de la vida oculta en su interior, capaz de ser armonizada por el hombre mediante el fiel cumplimiento de los preceptos, y descrita por la teoría de las Sefirot, concebidas como entidades conceptuales, conformadas por letras y números, utilizadas por Yavéh para posibilitar la realidad de todo lo creado. El Zohar postula un modelo de hermenéutica simbólica, contrario al método alegórico utilizado por la cábala extática o profética practicada por los seguidores de Abraham Abulafia (Idel, Cábala 271-329), al tiempo que rescata un tipo especial de experiencia visual que entiende como medio principal de revelación y gnosis del plano divino, a partir de la estrecha relación entre el estudio profundo del texto sagrado y la devequt o proceso de apego o adhesión del individuo a la voluntad del Dios de Israel. Gracias al compromiso con dicho proceso, los mekubalim confirmaban el sentido oculto de las mitzvot $\mathrm{u}$ obligaciones que los constituían como judíos. Ambos aspectos comparten un territorio común, como sugerimos antes, con la dinámica de la visión de las liras centrales de Cántico espiritual.

El punto de vista zohárico se aprecia claramente en Sava de-Mishpatim, es decir, el "discurso del Anciano" de la sección Mishpatim del Zohar (vol. II, 94b-114a), destinado a la exégesis de los capítulos XXI a XXIV del libro de Éxodo. Este texto, parte esencial de la sección, es una de las cumbres de la literatura cabalística. De compleja estructura, se trata básicamente de una narración centrada en el discurso pronunciado por un misterioso anciano que, bajo la miserable apariencia de un borriquero, se presenta como gran cabalista ante dos discípulos de R. Simeón bar Yo ai, el mítico tanna o sabio palestino del siglo II de la era común a quien la tradición atribuye la redacción del Zohar. El elaborado discurso de este anciano trata de los misterios del alma, las transmigraciones y el destino del levirato, a partir de una interpretación del código legal de la Torá relativo al trato que se ha de dar al esclavo hebreo. Por debajo de los presupuestos temáticos que aparecen en este texto de la cábala, en él se pone en juego precisamente, como en todo el corpus zohárico, la centralidad del modo visual de conocimiento del sentido más profundo de la palabra de Yahveh, mediante el uso de parábolas o mashalim, utilizadas 
para la explicación visual de conceptos cognitivos. Según una antigua tradición rabínica que el Zohar retoma, la actividad de exégesis del texto revelado está profundamente ligada con la teofanía sinaítica. De tal modo, desde los postulados de un exégeta místico judío, la relación hermenéutica que él establece con la Torá le permite ver nuevamente a Dios tal como fue visto en el acontecimiento histórico de la revelación en el Monte Sinaí, actualizando así el conocimiento oculto de las Sefirot que el Pueblo de la Alianza tuvo entonces el privilegio de recibir. Según leemos:

Las diez palabras de la Torá [el Decálogo] [...] fueron grabadas sobre las tablas de piedra, y todo lo que estaba oculto en ellas fue visible a sus ojos [...] todo fue entendido en las mentes de Israel y todo fue revelado a sus ojos [...] porque ellos veían con sus ojos el resplandor [zohar] de la Gloria de su Maestro (Zohar II, 93b-94a) ${ }^{5}$.

Por otra parte, una interpretación propuesta por este texto cabalístico central (Zohar II, 82 b) ${ }^{6}$ establece que los judíos que participaron de la gnosis visionaria del Sinaí alcanzaron el estatus simbólico de Moisés, el prototipo de místico judío (Zohar III, 132b), por haber atravesado por una experiencia superior a la de otros profetas. Esta posición de privilegio es compartida, entendemos, por los iniciados en la cábala teosófica y Juan de la Cruz, ya que guarda relación directa con un tipo de experiencia visual -con manifestaciones textuales similares- que excedió el alcance tradicional de la experiencia profética que vivieron Abraham, Isaac y Jacob, o la visión que el mismo Ezequiel tuvo en Babilonia. Más allá de la estéril discusión acerca de las formas o el alcance de la devekut o unión mística para los exégetas del círculo del Zohar, su relación con la perseguida por Abraham Abulafia y los seguidores de la cábala extática ${ }^{7}$ o su posible vinculación con la experiencia mística sanjuanista, lo que aquí señalamos simplemente es la coincidencia de un tipo privilegiado de conocimiento con correlatos textuales rastreables en ambos corpus.

En este sentido, lo que hace tan especial la escritura mística de Juan de la Cruz -acercándola a la exégesis zohárica- es precisamente aquello que la diferencia del trabajo con el lenguaje de otros místicos cristianos. Mientras tradicionalmente el de la mayoría de estos últimos refleja un creciente interés por hacer más comprensibles los misterios, tropos y símbolos de la Escritura, en el Reformador del Carmelo -como en Moshé de León y los teósofos judíos-hay una especial inclinación por una propedéutica

5 Véase, asimismo, I, 91a, II, 82b y $156 \mathrm{~b}$.

${ }^{6}$ Atribuida a Rabí Iosef y contraria a la opinión de R. Eleazar, quien entendía que en la teofanía sinaítica el pueblo de Israel solo tuvo una experiencia profética "normal" u "ordinaria". A este respecto téngase en cuenta, muy especialmente, el análisis de Wolfson en "The Hermeneutics of Visionary Experience".

${ }^{7}$ Para un análisis de la diferencia entre la Cábala teosófica como ideología de la unificación y la Cábala extática y su búsqueda del hombre perfecto como intelecto perfecto que experimenta una unión mística con el intelecto celestial, vide Idel, Cábala, de manera particular 278-279. 
que incentive y logre que los iniciados o perfectos experimenten las verdades de la fe. En palabras de Moshé Idel:

Para el cabalista la comprensión del sentido interior del texto o de la tradición [...] implica un cambio radical en la percepción de la Torá, [...] una experiencia total, que va más allá de la contemplación pasiva del sentido simbólico de un texto. Más que una interiorización de contenidos específicos, este estudio [experiencial] suscita el establecimiento de una relación íntima [con el texto] (Cábala 305-306, con nuestro énfasis).

Teniendo en cuenta esta idea central de experiencia total -aplicable tanto a la lectura como a la escritura de un texto místico-, apreciemos cómo el Zohar contrasta la teofanía del Monte Sinaí con la "Visión del Carro" del libro de Ezequiel (1: 1-28; 3: 12-14):

Cuando Dios se reveló a sí mismo en el Monte Sinaí, todos los de Israel vieron como quien ve desde una luz en un cristal. Y desde esa luz cada uno vio lo que Ezequiel [...] no vio. ¿Por qué? [...] [porque] Ezequiel vio como alguien que ve desde atrás de muchas paredes (Zohar II, 82b).

En contraposición, afirmará más adelante:

Cuando la Torá fue dada a Israel, ellos [tuvieron] una visión diferente y vieron las gradaciones superiores, fijaron la vista directamente [en ellas] anhelando contemplar la Gloria de su Maestro. Así, ellos vieron la gloria celestial y al Bendito, nada más (Zohar I, 91a).

Y en adición a esto, dirá:

¿Qué distingue a Moisés de otros profetas? [El] fijó su mirada en un cristal que brilla, mientras otros profetas lo hicieron sólo en un cristal que no brilla [y así, Moisés] conoció la palabra [de Dios] claramente (Zohar I, 170b-171a).

De igual modo que los citados pasajes de este modelo teosófico judío adjudican a Ezequiel una experiencia visual de Dios de nivel inferior a la teofanía compartida simbólicamente por Moisés y su pueblo, su vinculación con las liras centrales de Cántico espiritual pone de manifiesto una experiencia similar y un medio común utilizado en ambos corpora para expresar una revelación extraordinaria. Por un lado, en el texto zohárico entendemos que Israel vio a Dios claramente (como quien ve desde una luz en un cristal), lo que nos recuerda el comentario de $C A$ 11:3: "Llámala «cristalina» a la fe [...] porque tiene las propiedades [del] cristal en ser pura en las verdades [...], clara [y] limpia [lo que la hace digna de traslucir los ojos del Amado]" (Obras 469). Por otro, apreciamos que la experiencia requirió, al igual que en la estrofa central del texto sanjuanista, de una mediación, de un cristal a través del cual pueda manifestarse en el plano simbólico la mirada de Dios, morigerándola, sin lo cual sería irresistible aun para un profeta. Para este fin, el Zohar amplía notablemente el significado original de la palabra aramea azu 
("visión" o "apariencia”), agregándole el de "cristal”, que encontramos también en el campo semántico de la fuente sanjuanista. En el caso de los teósofos judíos, la sinonimia les permitía pensar en experiencias de diversa jerarquía simbólica. Así, por ejemplo, afirmaban que el profetismo de Abraham, Isaac o Jacob alcanzó históricamente un menor privilegio simbólico que el de la experiencia mosaica, pues aquellos profetas solo fueron dignos de visualizar ciertos aspectos de ha-Shem reflejados en la Shekhinah, el aspecto femenino de Dios, símbolo de la última Sefirá, en la cual todas las imágenes aparecen $(\mathrm{I}, 91 \mathrm{a})^{8}$. Esta última era entendida como una especie de cristal opaco sin luz propia, y cuyo brillo era el resultado del reflejo de las luces de todas las demás gradaciones de Yahveh. Por el contrario, la superior jerarquía simbólica que lograron Moisés y su pueblo como consecuencia de la teofanía en el Monte Sinaí -gracias a la que tuvieron el privilegio de ver, no un reflejo, sino "cara a cara" aspectos más nítidos de la gloria de Dios-, era compartida, por carácter transitivo, por todos los teósofos judíos y se la vinculaba estrechamente con Tiféret, la sexta Sefirá, también llamada pilar central o cristal luminoso.

Las características más importantes de este cristal mediador son, en esencia, dos: el hecho de que tiene luz propia, como resultado de su capacidad para permitir el conocimiento visual del texto sagrado (al dejar que la mirada de Dios se vislumbre); y su centralidad, que comparte con la de la fuente en Juan de la Cruz. Así como en la estructura de Cántico las liras del primer encuentro con el Amado -mediado por la mirada- ocupan el centro de la escena, en la tradición de la Cábala, Tiféret (la Belleza o Misericordia de Yavéh) armoniza los pares opuestos representados por las Sefirot Hésed (su Bondad absoluta), y Din (su Justicia). En consecuencia, el cristal de ínsita luz que posibilita, para quienes practicaban la Cábala teosófica, la gnosis visual del sentido más profundo de la palabra de ha-Shem cumple una función similar a la de la fuente de la estrofa XI de las Canciones, escenario luminoso y exclusivo para el encuentro visual inicial y la identificación amorosa entre el alma y su Amado, que solo la piadosa mirada de este último hace posible al verbalizar una experiencia fundamental y constitutiva en ambas tradiciones místicas: para el cristianismo, la de ser dignos de ser mirados por Dios; para el judaísmo, la de ser considerados íntegros por Yahveh, cuyos matices hemos de analizar en un trabajo de propósito.

Es por este motivo que Juan de la Cruz puede afirmar $(C A, 11: 4)$ : "la fe [esto es, la fuente, el cristal] nos da y comunica al mismo Dios, pero cubierto con plata de fe, y no por eso nos le deja de dar en la verdad" (Obras 470). Y no por otra razón, al comentar el primer verso de la Canción XI, exclusiva de la segunda redacción ("Descubre tu presencia", Obras 607-609), explicando las "tres maneras de presencia [...] de Dios en el alma" (natural, que le da vida; espiritual, que le infunde perfección; y afectiva, con la que Dios le hace sentir el sumo bien de su amor), puede asociar su propia experiencia visual, intelectual y emotiva con la del prototipo de místico judío, diciendo: "lo mismo le acaeció a Moisés en el Monte Sinaí, que, estando allí en la presencia de Dios [echó

${ }^{8}$ Cf. la nota 566 de la Pritzker Edition (2004), vol II, p. 73. 
de ver] tan altos y profundos visos de la alteza y hermosura de la divinidad de Dios encubierta" (Obras 608).

Llegados hasta aquí, si recordamos ahora la pertinaz recurrencia de San Juan de la Cruz a la Biblia hebrea como tribunal último de su experiencia mística, no resultará extraño que en el eje discursivo de Cántico espiritual, entendido como genial refundición del Cantar de los Cantares -el texto canónico judío con mayor número de interpretaciones místicas-, la fuente, es decir, el cristal, tenga luz propia al traslucir la mirada del Amado, que su amada, el alma, es capaz de sostener simbólicamente porque es mirada por aquél, al menos por un instante, en la apoteosis de la lira XII.

El privilegiado estatus simbólico que comparten el maskil de la tradición cabalística y nuestro místico carmelita puede corroborarse desde una lectura pertinente de un pasaje de Sava de-Mishpatim (Zohar, vol. II, 98b), que dice así:

El Sagrado, alabado sea Él, penetra en todas las cosas [o palabras] ocultas que Él ha hecho dentro de la Sagrada Torá y todo se encuentra en la Torá. Y la Torá revela esa cosa [o palabra] oculta y después se cubre inmediatamente con otro ropaje donde se esconde y no es revelada. Y aunque esa cosa [o palabra] está oculta en su ropaje, los sabios, que están llenos de ojos, la ven desde dentro de su ropaje. Cuando esa cosa [o palabra] es revelada, antes de que entre en su ropaje, el que tiene los ojos abiertos lanza sus ojos sobre ella. Y aunque [la cosa o palabra] se cubre inmediatamente, no se aparta de sus ojos.

Encontramos aquí un claro ejemplo del lenguaje visual que propone el Zohar, en un entramado textual que refleja cómo Dios esconde asuntos secretos dentro de la Torá para vestirlos con un ropaje; y, al mismo tiempo, cómo el mekubal -el iniciado en la exégesis mística- tiene el privilegio de ver los secretos ocultos antes de que vuelvan a ser recubiertos. De allí que el cabalista sea llamado el "sabio lleno de ojos", capaz de lanzar y sostener su mirada -en el sentido de ser digno de participar de-el misterio más profundo del texto revelado. Similar idea es connotada, en Cántico espiritual $(C A)$, por el conjunto estrófico XI y XII, donde la novedad de que la fuente muestre fugazmente a la amante los "ojos deseados" de aquel a quien ama y busca "con gemido" (Obras 436), está implícita en el "Apártalos, Amado / que voy de vuelo" (Obras 472), que profundiza y enriquece la significación a partir de lo que elide. Diríase que el alma de Juan de la Cruz, que tan intensamente sentía al Amado en su interior que "le [parecía] la [estaba] ya siempre mirando" ( $C A, 11,5$; Obras 470), fue digna también de sostener su mirada como un auténtico "sabio lleno de ojos", para recuperar luego hermenéuticamente, en liras y comentarios de refinado simbolismo, su propia experiencia mística. Como acertadamente afirmó Mancho Duque -con un énfasis aplicable a la concepción del lenguaje en el Zohar-, el simbolismo sanjuanista "tiene unas raíces tan profundas que no "traduce" una 
experiencia, sino, [por el contrario, nos permite comprender que] la propia experiencia es en sí simbólica" (Palabras y símbolos en San Juan de la Cruz 137).

Decimos también que Juan de la Cruz es un maskil en términos de la exégesis que el Zohar realiza del famoso pasaje del libro de Daniel del que toma su nombre, "Y los iluminados [ha-maskilim] brillarán como el resplandor [zohar] del cielo" (Daniel 12:3).

En este sentido, en la conocida exégesis de Zohar Hadash, Matnitin, 105a, leemos:

¿Quiénes son los iluminados? Aquellos que saben cómo contemplar [...] y conocen el secreto de la Sabiduría. [...] Estos brillan como el resplandor superior. Y se dice "los iluminados" [ha-maskilim] más que "los conocedores" [ha-yode'im] porque estos son verdaderamente quienes contemplan los secretos interiores, escondidos, que no son revelados ni transmitidos a cualquier persona" (Cit. en Wolfson 383. La traducción es nuestra).

Una precisión filológica ayudará aquí a comprender mejor la exégesis cabalística del pasaje de Daniel y la figura del "sabio lleno de ojos" que resume el privilegiado estatuto simbólico compartido por los místicos del círculo del Zohar y Juan de la Cruz. La palabra hebrea maskil, participio activo del verbo lehaskil, con sus acepciones tradicionales de "discernir", "lograr sabiduría" o "mirar", es un término técnico aplicado en la tradición de la Cábala a los teósofos; pues éstos, como recuerda Wolfson, ubicaban "la visión de Dios [de la Torá] en el centro de su adoración, [determinada ésta por] una dialéctica del [...] mirar y el ser mirado" (285-286, en nuestra traducción). Así, la raíz trilítera del término, que encierra la idea de comprensión a través de la mirada-como en griego theoria, o en la tradición neoplátonica latina contemplatio,-, nos permite pensar en Juan de la Cruz como en un "iluminado", desde la perspectiva que así consideraba al "sabio que comprende por sí mismo aquellas cosas que ningún hombre puede decir con su boca [y por lo tanto brillará] como el resplandor [del] cielo de Moisés" (Zohar II, 23a). Este último es otro de los nombres con los que en el círculo de la Cábala castellana se conocía a la Sefirá Tiféret, que se encontraba “[oculta] en el centro del edificio [de Yahvé]" (ibídem), de centralidad similar (según dijimos antes) a la que ocupa la fuente en el poema sanjuanista, y que sólo Moisés y el pueblo de la Alianza fueron dignos de alcanzar cuando contemplaron, solitarios, los "colores superiores, ocultos e invisibles" de Dios (Zohar II, 23b).

Detengámonos por último, muy brevemente, en la preeminencia del lenguaje visual que comparten la "parábola de la princesa" de Sava de-Mishpatim y el conjunto estrófico XI y XII de las Canciones $(C A)$. El relato de la hermosa princesa (en arameo rehimatá, es decir, literalmente "amada") de Zohar II, 99a-b, que, oculta en su palacio, invoca y 
seduce con su amor a su amante (rehimáh) para que se acerque y pueda, finalmente, unirse con ella en matrimonio, constituye el pasaje de mayor densidad significativa de Sava de-Mishpatim, cuya interpretación simbólica excede el alcance de este trabajo. Baste decir que, en el plano alegórico, la princesa es la Torá oculta detrás de los cuatro niveles tradicionales de exégesis cabalística, presentes en el acrónimo PaRDeS-el jardín de la antigua leyenda rabínica (Talmud Babilónico, Haguigá 14b): P[eshat] o literal, R[emez] o alegórico, D[erash] o homilético, y $\boldsymbol{S}$ [od] o místico (Idel, "Kabbalistic Exegesis" 457459). La Escritura, como la princesa, aparece y se desvanece rápidamente ante el amante, el cabalista que es guiado gradualmente al nivel más profundo de conocimiento del texto revelado. Al principio, la doncella insinúa su existencia mediante simples alusiones que solo comprende quien la ama, revelándose paulatinamente de manera discursiva, hasta que, en la culminación del proceso de descubrimiento, queda desnuda ante él, como frente a un esposo que conoce visualmente todos sus secretos. Así lo afirma el texto:

La Torá se revela un instante por amor a sus amantes para despertar en ellos amor puro. [...] Este es el camino [...] Primero comienza a revelarse a un hombre [mediante] señales. Si él [no] entiende lo manda llamar y le dice 'simple' y dice a sus mensajeros: 'decid a ese necio que venga aquí y converse conmigo'. Cuando él viene, ella empieza a hablarle, primero desde detrás de la cortina que ella tiende [...] sobre las palabras [que resulten] accesibles a su entendimiento, de manera que él pueda progresar poco a poco. [...] Luego ella le habla desde detrás de un delgado velo, [mediante] adivinanzas y parábolas. [...] por último [...] se le muestra cara a cara [y le descubre] todos sus misterios ocultos y todos los caminos [...] guardados desde siempre en su corazón (Zohar II, 99a-b).

Lo antedicho evoca el comentario de Juan de la Cruz cuando habla de "la presteza del esconderse y mostrarse [que] suele hacer el Amado [...] aumentando la pasión y apetito de [su] vista" (CA 1: 15-16; Obras 444-445). De igual modo, en la exégesis del Zohar puede apreciarse cómo, en concordancia con el modo de conocimiento centrado en la mirada propuesto por este modelo teosófico, el principal medio de revelación y unión es el visual, a pesar de la reiteración de la escucha en el proceso de descubrimiento del sentido oculto y esencial de la palabra de Yahveh. La preeminencia de dicho medio por sobre el auditivo remite, también, al esquema que siguen las Canciones, en las que luego del comienzo vertiginoso de la búsqueda del amado, donde prevalece lo discursivo, arribamos al locus privilegiado de las liras centrales en las que se verifica el alumbramiento inicial de la mirada unitiva y la transformación amorosa de los amantes.

El progreso desde lo auditivo hacia lo visual que señalamos en la "parábola de la princesa", puede reconocerse en el texto sanjuanista destacando simplemente algunos vocablos clave en las secciones previas al conjunto estrófico XI-XII de CA (Obras 436-437). Entre ellos: "salí tras ti, clamando" (estrofa 1); "Pastores [...] / decidle que adolezco" (estrofa 2); ¡Oh bosques y espesuras [...] / decid si por vosotros ha pasado!" (estrofa 4); "No quieras enviarme [...] [ya] más mensajero que no saben decirme lo que quiero (estrofa 6); "Y todos $[\ldots]$ me van mil gracias refiriendo, $[\ldots]$ y déjame muriendo un no sé qué que quedan balbuciendo" (estrofa 7). La progresividad del esquema se completa y refuerza cohesivamente en tres momentos (ibíd) que anuncian o prefiguran 
la experiencia visual cuasi absoluta que ha de ocurrir en el centro mismo del Cántico, actualizando, como dijimos, un modo prevalente -no excluyente- para el conocimiento de Dios. Nos referimos a los versos "[pastores] si por ventura vierdes" (estrofa 2); "[el Amado] pasó por estos sotos [...] / e yéndolos mirando" (estrofa 5) y, por último, en el umbral de la experiencia inefable, "y véante mis ojos" (estrofa 10).

En definitiva, todo el trabajo de orfebrería visual que apreciamos en los textos elegidos, no hace sino confirmarnos en nuestro propio privilegio de lectores, infinitamente alejado del que compartieron los teósofos judíos y Juan de la Cruz: el de un conocimiento que los convirtió en verdaderos artistas de la experiencia y del idioma.

\section{BIBLIOGRAFÍA}

Baruzi, Jean. 1924. San Juan de la Cruz y el problema de la experiencia mística. Prólogo de José Jiménez Lozano. Postfacio de Rosa Rossi. Traducción de Carlos Ortega. Valladolid: Junta de Castilla y León, 2001.

Idel, Moshé. Cábala: nuevas perspectivas. 1988. Trad. María Tabuyo y Agustín López, México: FCE, Ediciones Siruela, 2006.

"Kabbalistic Exegesis". Hebrew Bible, Old Testament: the history of its interpretation, I/2: The Middle Ages. Ed. Magne Saebø. Göttingen: Vandenhoeck \& Ruprecht, 2000. 456-466.

Mancho Duque, María Jesús. "San Juan de la Cruz, prototipo de escritor místico". Palabras y símbolos en San Juan de la Cruz. Madrid: FUE-Universidad Pontificia de Salamanca, 1993. 15-24.

San Juan de la Cruz. Obras completas. Edición crítica, notas y apéndices por Lucinio Ruano de la Iglesia, 11 ${ }^{\mathrm{a}}$ ed. Madrid: EDICA, 1982.

Cántico espiritual y poesía completa. Edición, prólogo y notas de Paola Elia y María Jesús Mancho Duque. Estudio preliminar de Domingo Ynduráin. Madrid: Crítica, 2002.

The Zohar. Pritzker Edition. Translation and Commentary by Daniel C. Matt. California: Stanford University Press, 2004-2009 (in progress). Vol. I, Z1:1a-76b (2004); Vol. II, Z1: 76b-165b (2004); Vol. III, Z1: 166a-251a (2006); Vol. IV, Z2: 2a-94a (2007); Vol. V, Z2: 94b-179a (2009).

Valente, José Ángel "El ojo de agua". Variaciones sobre el pájaro y la red, precedido de la piedra y el centro. Barcelona: Tusquets, 1991. 76-84.

Wilhelmsen, Elizabeth. Cognition and Communication in John of the Cross. Frankfurt/M., Bern, New York: Peter Lang, 1985.

“San Juan de la Cruz: percepción espiritual e imagen poética". Bulletin Hispanique. LXXXVIII/3-4 (1986): 293-319.

Knowledge and Symbolization in Saint John of the Cross. Frankfurt/M., Berlin, Bern, New York, Paris, Wien: Peter Lang, 1993. 
Wolfson, Elliot R. "The Hermeneutics of Visionary Experience: Revelation and Interpretation in the Zohar". Religion. 18 (1988): 311-345.

Through a speculum that shines. Vision and imagination in Jewish medieval mysticism. 1994. Princeton, NJ: Princeton University Press, 1997. 